\title{
Head-to-Head Comparison of Rapid and Automated Antigen Detection Tests for the Diagnosis of SARS-CoV-2 Infection
}

\author{
Julien Favresse ${ }^{1,2, *}$, Constant Gillot ${ }^{2}{ }^{\mathbb{D}}$, Maxime Oliveira ${ }^{2}$, Julie Cadrobbi ${ }^{1}$, Marc Elsen ${ }^{1}$, Christine Eucher $^{1}$, \\ Kim Laffineur ${ }^{1}$, Catherine Rosseels ${ }^{1}$, Sandrine Van Eeckhoudt ${ }^{3}$, Jean-Baptiste Nicolas ${ }^{3}$, Laure Morimont ${ }^{2,4}$, \\ Jean-Michel Dogné ${ }^{2}$ and Jonathan Douxfils ${ }^{2,4}$ ()
}

1 Department of Laboratory Medicine, Clinique St-Luc Bouge, 5004 Namur, Belgium; julie.cadrobbi@slbo.be (J.C.); marc.elsen@slbo.be (M.E.); christine.eucher@slbo.be (C.E.); kim.laffineur@slbo.be (K.L.); catherine.rosseels@slbo.be (C.R.)

2 Department of Pharmacy, Namur Research Institute for Life Sciences, University of Namur, 5000 Namur, Belgium; constant.gillot@unamur.be (C.G.); maxime.oliveira@qualiblood.eu (M.O.); laure.morimont@unamur.be (L.M.); jean-michel.dogne@unamur.be (J.-M.D.); jonathan.douxfils@unamur.be (J.D.)

3 Department of Internal Medicine, Clinique St-Luc Bouge, 5004 Namur, Belgium; sandrine.vaneeckhoudt@slbo.be (S.V.E.); jeanbaptiste.nicolas@slbo.be (J.-B.N.)

4 Qualiblood S.A., 5000 Namur, Belgium

* Correspondence: j.favresse@labstluc.be

check for updates

Citation: Favresse, J.; Gillot, C.; Oliveira, M.; Cadrobbi, J.; Elsen, M.; Eucher, C.; Laffineur, K.; Rosseels, C.; Van Eeckhoudt, S.; Nicolas, J.-B.; et al. Head-to-Head Comparison of Rapid and Automated Antigen Detection Tests for the Diagnosis of SARS-CoV-2 Infection. J. Clin. Med. 2021, 10, 265. https://doi.org/10.3390/jcm10020265

Received: 10 December 2020 Accepted: 11 January 2021 Published: 13 January 2021

Publisher's Note: MDPI stays neutral with regard to jurisdictional clai$\mathrm{ms}$ in published maps and institutional affiliations.

Copyright: (C) 2021 by the authors. Licensee MDPI, Basel, Switzerland. This article is an open access article distributed under the terms and conditions of the Creative Commons Attribution (CC BY) license (https:// creativecommons.org/licenses/by/ $4.0 /)$.

\begin{abstract}
Background: The detection of SARS-CoV-2 RNA in nasopharyngeal samples through real-time reverse transcription-polymerase chain reaction (RT-PCR) is considered the standard gold method for the diagnosis of SARS-CoV-2 infection. Antigen detection (AD) tests are more rapid, less laborious, and less expensive alternatives but still require clinical validation. (2) Methods: This study compared the clinical performance of five AD tests, including four rapid AD (RAD) tests (biotical, Panbio, Healgen, and Roche) and one automated AD test (VITROS). For that purpose, 118 (62.8\%) symptomatic patients and $70(37.2 \%)$ asymptomatic subjects were tested, and results were compared to RT-PCR. (3) Results: The performance of the RAD tests was modest and allowed us to identify RT-PCR positive patients with higher viral loads. For $\mathrm{Ct}$ values $\leq 25$, the sensitivity ranged from 93.1\% (95\% CI: 83.3-98.1\%) to 96.6\% (95\% CI: 88.1-99.6\%), meaning that some samples with high viral loads were missed. Considering the $\mathrm{Ct}$ value proposed by the CDC for contagiousness (i.e., Ct values $\leq 33$ ) sensitivities ranged from $76.2 \%$ (95\% CI: $65.4-85.1 \%$ ) to $88.8 \%$ (95\% CI: 79.7-94.7\%) while the specificity ranged from $96.3 \%$ (95\% CI: $90.8-99.0 \%)$ to $99.1 \%$ (95\% CI: $95.0-100 \%)$. The VITROS automated assay showed a 100\% (95\% CI: 95.5-100\%) sensitivity for Ct values $\leq 33$, and had a specificity of $100 \%$ (95\% CI: 96.6-100\%); (4) Conclusions: Compared to RAD tests, the VITROS assay fully aligned with RT-PCR for Ct values up to 33, which might allow a faster, easier and cheaper identification of SARS-CoV-2 contagious patients.
\end{abstract}

Keywords: COVID-19; SARS-CoV-2; antigen testing; manual assay; automated assay

\section{Introduction}

Currently, the revelation of SARS-CoV-2 RNA through real-time reverse transcriptionpolymerase chain reaction (RT-PCR) from nasopharyngeal swab samples is considered the standard gold method for the diagnosis of SARS-CoV-2 infection. The targeted genes may include a combination of $N, E, R d R p$, orf1 $a$, and orf1b genes [1,2]. However, even if the RT-PCR method is highly sensitive, positive SARS-CoV-2 samples do not always allow definitive conclusions about whether the subject is contagious or not [3]. This can be partly assessed by the cycle threshold $(\mathrm{Ct})$ value, which has been correlated to the amount of viral RNA in the sample, informing on the viral load and infectivity [4].

In addition, in most laboratories, the analysis throughput of RT-PCR testing is limited because it requires a high workload, skillful operators, expensive instrumentation, and 
crucial biosafety measures [5,6]. In contrast, antigen detection (AD) tests are more rapid, less laborious, less expensive, and require only a comparatively short training period. Currently, there are approximately 100 different AD tests on the market [7]. Head-to-head comparisons of $\mathrm{AD}$ test performance for SARS-CoV-2 detection are scarce. The majority of the studies only included few patients, precluding a wide characterization of the "reallife" performance of these devices [3,8-23]. Recently, a Cochrane study found an average sensitivity of only $56.2 \%$ (95\% confidence interval (CI): $29.5-79.8 \%$ ) for rapid AD (RAD) tests [11]. Independent reporting of automated AD test performance remains limited [18].

This study aimed to compare the clinical performance of 4 RAD tests ((i) the Biotical SARS-CoV-2 Ag card, (ii) the Panbio ${ }^{\mathrm{TM}}$ COVID-19 Ag Rapid Test Device, (iii) the Coronavirus Ag Rapid Test Cassette, and (iv) the Roche SARS-CoV-2 Rapid Antigen Test)) and one automated AD test (VITROS Immunodiagnostic Products SARS-CoV-2 Antigen test), to the results of the RT-PCR.

\section{Material and Methods}

\subsection{Patients and Sample Collection}

This study was conducted from 17 November to 25 November 2020 at the clinical biology laboratory of the Clinique Saint-Luc (Bouge, Namur, Belgium). Nasopharyngeal samples from 188 patients (104 females (median age $=54$ years; min-max: 5-97 years) and 84 males (median age: 57 years; min-max: 1-94 years)) who presented at our institution for SARS-CoV-2 testing were included. One hundred and eighteen $(62.8 \%)$ were symptomatic patients, and $70(37.2 \%)$ were asymptomatic subjects. In symptomatic patients, the median time since symptom onset was three days (interquartile range (IQR): 2-4 days). Information on the days since the onset of symptoms was collected from medical records and was available for all patients. Nasopharyngeal samples were collected using eSwab liquid preservation medium (Copan Italia, Brescia, Italy) or Vacuette Virus Stabilization (Greiner Bio-One, Kremsmünster, Austria) tubes. The same tube was used for both RT-PCR and antigenic assessments. The study protocol was in accordance with the Declaration of Helsinki and was approved by the Medical Ethical Committee of Saint-Luc Bouge (Bouge, Belgium, approval number B0392020000005).

\subsection{Analytical Procedures}

The 4 RAD tests included were: (i) the Biotical SARS-CoV-2 Ag card (Biotical Health, Madrid, Spain), (ii) the Panbio ${ }^{\mathrm{TM}}$ COVID-19 Ag Rapid Test Device (Abbott, Chicago, IL, USA), (iii) the Coronavirus Ag Rapid Test Cassette (Healgen Scientific, Houston, TX, USA) and (iv) the Roche SARS-CoV-2 Rapid Antigen Test (Roche Diagnostics, Basel, Switzerland). Samples identified as positive at both the control line and test line were regarded as SARS-CoV-2 antigen-positive, and samples having only the control line were regarded as SARS-CoV-2 antigen-negative. The automated AD test was the VITROS Immunodiagnostic Products SARS-CoV-2 Antigen test (Ortho Clinical Diagnostics, Raritan, NJ, USA) performed on the VITROS 3600 Immunodiagnostic System (Ortho Clinical Diagnostics). A signal $\geq 1$, as rendered by the analyzer, was considered positive. The target of the $5 \mathrm{AD}$ tests was the nucleocapsid, i.e., the main antigen used in available AD tests on the market [7]. Table 1 summarizes the characteristics and procedures of these $\mathrm{AD}$ tests. The viral transport media was used instead of the swab provided in the kits in order to allow the assessment of 5 different $\mathrm{AD}$ tests on the same sample. The analyses were performed according to the recommendations of the manufacturers.

Two independent operators (CG and MD) interpreted the results of the four RAD tests. In case of disagreement (i.e., in case of low band intensity), a third-blinded operator (JD) interpreted the result to find a consensus result. All operators were blinded to RT-PCR results and clinical data while performing or interpreting $\mathrm{AD}$ tests. The results of the four RAD tests were read after the reaction times recommended by the manufacturers; to note: if the manufacturer recommended reading the result between a certain interval of times 
(e.g., between 15 and $20 \mathrm{~min}$ ), two readings were performed at the lowest and highest recommended times.

Table 1. Characteristics of antigenic tests used in this study.

\begin{tabular}{|c|c|c|c|c|c|}
\hline Test & Manufacturer & Process & Target & Technological & Procedure \\
\hline $\begin{array}{c}\text { Biotical SARS-CoV-2 } \\
\text { Ag card }\end{array}$ & Biotical health & Manual & Nucleocapsid & Immunochromatographic & $\begin{array}{l}50 \text { parts sample: } 50 \text { parts buffer; } \\
\text { reading at } 10 \text { min. Positive if both } \\
\text { control and test line are present. } \\
\text { Negative if only the control band is } \\
\text { present }\end{array}$ \\
\hline $\begin{array}{l}\text { Panbio }^{\mathrm{TM}} \text { COVID-19 } \\
\text { Ag Rapid Test Device }\end{array}$ & Abbott & Manual & Nucleocapsid & Immunochromatographic & $\begin{array}{l}46 \text { parts sample: } 54 \text { parts buffer; } \\
\text { reading between } 15 \text { and } 20 \text { min. } \\
\text { Positive if both control and test line } \\
\text { are present. Negative if only the } \\
\text { control band is present }\end{array}$ \\
\hline $\begin{array}{l}\text { Coronavirus Ag } \\
\text { Rapid Test Cassette }\end{array}$ & $\begin{array}{l}\text { Healgen } \\
\text { Scientific }\end{array}$ & Manual & Nucleocapsid & Immunochromatographic & $\begin{array}{l}50 \text { parts sample: } 50 \text { parts buffer; } \\
\text { reading between } 15 \text { and } 20 \text { min. } \\
\text { Positive if both control and test line } \\
\text { are present. Negative if only the } \\
\text { control band is present }\end{array}$ \\
\hline $\begin{array}{l}\text { Roche SARS-CoV-2 } \\
\text { Rapid Antigen Test }\end{array}$ & $\begin{array}{c}\text { Roche } \\
\text { Diagnostics }\end{array}$ & Manual & Nucleocapsid & Immunochromatographic & $\begin{array}{l}50 \text { parts sample: } 50 \text { parts buffer; } \\
\text { reading between } 15 \text { and } 30 \text { min. } \\
\text { Positive if both control and test line } \\
\text { are present. Negative if only the } \\
\text { control band is present }\end{array}$ \\
\hline $\begin{array}{l}\text { VITROS } \\
\text { Immunodiagnostic } \\
\text { Products } \\
\text { SARS-CoV-2 Antigen } \\
\text { test }\end{array}$ & $\begin{array}{l}\text { Ortho Clinical } \\
\text { Diagnostics }\end{array}$ & Automated & Nucleocapsid & Chemiluminescence & $\begin{array}{l}80 \text { parts sample: } 20 \text { parts buffer. } \\
\text { Positive if signal } \geq 1 \text {. Negative if } \\
\text { signal }<1 . \text { Time first result }=48 \mathrm{~min}, \\
\cong 150 \text { samples per hour }\end{array}$ \\
\hline
\end{tabular}

The RT-PCR for SARS-CoV-2 determination of nasopharyngeal swab samples was performed on a LightCycler ${ }^{\circledR}$ (Roche Diagnostics ${ }^{\circledR}$, Basel, Switzerland) 480 Instrument II (Roche Diagnostics ${ }^{\circledR}$ ) using the LightMix ${ }^{\circledR}$ (Roche Diagnostics ${ }^{\circledR}$ ) Modular SARS-CoV $E$-gene set. Cycle threshold values obtained by RT-PCR were used as a proxy for the viral load. All tests were performed within a maximum of $24 \mathrm{~h}$ after specimen collection.

\subsection{Statistical Analyses}

Descriptive statistics were used to analyze the data. Sensitivity was defined as the proportion of SARS-CoV-2 positive samples by the AD test initially categorized as positive by RT-PCR. Specificity was defined as the proportion of samples identified as negative by the AD test initially categorized as negative by RT-PCR. The sensitivity and specificity analyses were also performed by considering the $\mathrm{Ct}$ value determined as contagiousness instead of considering all $\mathrm{Ct}$ values as true positive results. Contagiousness was defined as the $\mathrm{Ct}$ values at which a viral culture has been reported negative, according to the literature (i.e., $\leq 25, \leq 33$, and $\leq 35$ ) $[4,8,24-28]$. Positive predictive values (PPV), negative predictive values (NPV), and test accuracy at different disease prevalence, i.e., 2, 5, 10, 15, 20, and 25\%, were also calculated. A Mann-Whitney test was used to assess differences between groups. A simple linear regression was computed to assess the potential association between antigen signal obtained on the automated platform (i.e., VITROS assay) and RT-PCR results (i.e., Ct values). The coefficients of variation [standard deviation/mean] $\times 100(\%)$ ] of the quantitative signals provided by the VITROS automated AD test have been assessed by using three patient samples analyzed 10 times in a row. Data analysis was performed using GraphPad Prism ${ }^{\circledR}$ software (version 9.0.0, California, CA, USA) and MedCalc ${ }^{\circledR}$ software (version 14.8.1, Ostend, Belgium). 


\section{Results}

\subsection{Population}

On the whole population, 96 patients $(51.1 \%$ ) had a positive RT-PCR (median Ct value: 22.3; min-max: 12.6-38.2). Among the symptomatic patients, 76 (64.4\%) had positive RT-PCR results (median Ct value: 21.2; min-max: 12.6-38.2). Among the asymptomatic subjects, $20(28.6 \%)$ had positive RT-PCR results (median Ct value: 25.9 ; min-max: 16.9-37.2). The Ct values were significantly lower in symptomatic patients compared to asymptomatic patients ( $p=0.01$, Supplemental Figure S1). In symptomatic patients, the time from symptom onset to sampling did not differ between RT-PCR positive (median: 3 days, IQR: $2-4$ days) or negative patients (median: 3 days, IQR: $2-5$ days) $(p=0.31$ ).

\subsection{RAD Tests Sensitivity}

The RAD tests were mostly effective to identify RT-PCR positive patients with higher viral loads (i.e., Ct values <25), with a sensitivity of $93.1 \%$ for the Biotical and the Panbio assays and of $96.6 \%$ for the Healgen and Roche assays at this threshold for positivity (Figure 1 and Supplementary Table S1). The Biotical, the Panbio, the Healgen, and the Roche RAD tests missed 4 (including one asymptomatic patient with a $\mathrm{Ct}$ value of 23.4), 4, 2 , and 2 patients with $\mathrm{Ct}$ values $\leq 25$, respectively (Figure 1 and Supplementary Table S1). For $\mathrm{Ct}$ values ranging from 25 to 30, RAD tests missed from 6 (31.6\%, Healgen assay, reading at $20 \mathrm{~min}$ ) to $13(68.4 \%$, Biotical assay) RT-PCR positive patients (Figure 1 and Table 2). Three asymptomatic subjects (i.e., Ct values of 25.5, 26.3, and 29.3) were not detected by any of the RAD tests. Discrepancies were observed between the different reading times. One Panbio result was positive after reading at $15 \mathrm{~min}(\mathrm{Ct}$ value $=28.7)$ but turned negative at $20 \mathrm{~min}$. On the other hand, one Panbio result was negative after reading at $15 \mathrm{~min}(\mathrm{Ct}$ value $=26.4$ ) but turned positive after $20 \mathrm{~min}$. Some discordances were also noted with the Healgen assay. Five negative results at $15 \mathrm{~min}$ turned positive at $20 \mathrm{~min}$. No discordance was observed with the Roche assay. For RT-PCR results with a Ct value $>30$, the number of RT-PCR positive patients detected was even lower (Table 2).
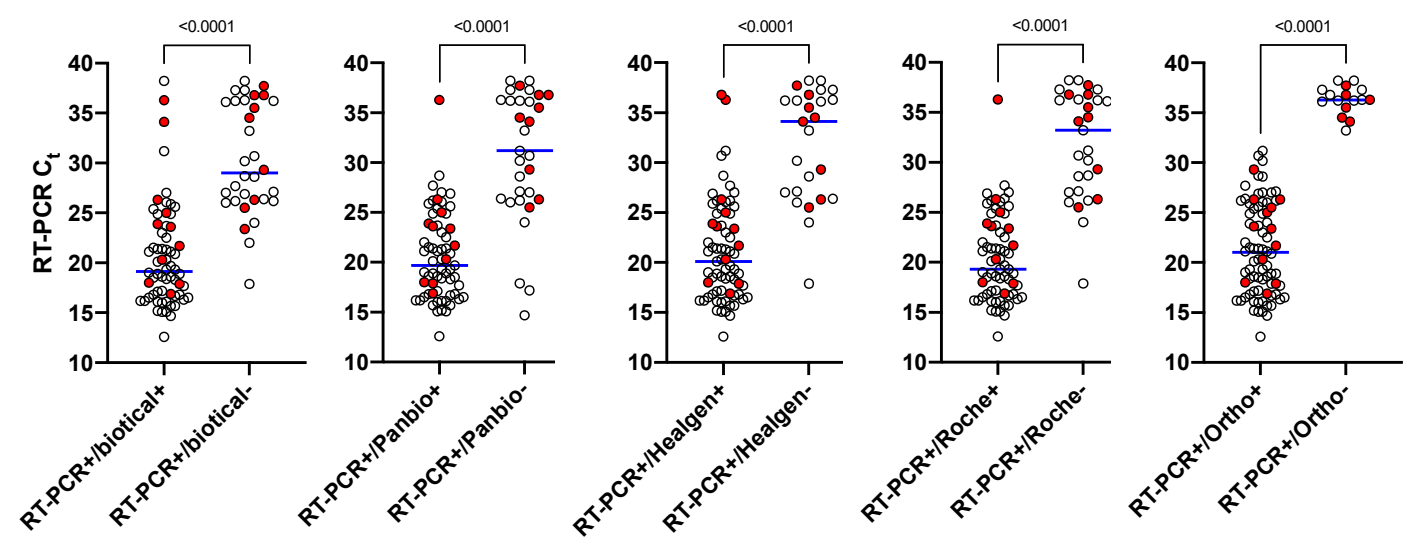

Figure 1. Graphical representation of positive and negative antigen results according to RT-PCR Ct values. A significant difference in the $\mathrm{Ct}$ value is observed between the positive and negative tests for each antigen method. Importantly, only the automated antigen shows no overlap between $\mathrm{Ct}$ values obtained for positive and negative samples. Samples from asymptomatic subjects are highlighted in red. 
Table 2. Sensitivity and specificity of RAD and automated antigen tests across different ranges of RT-PCR Ct values. Results in grey provide results of all RT-PCR values, including those with a Ct value $>33$ (min-max range: 12.6-38.2) for sensitivity and specificity.

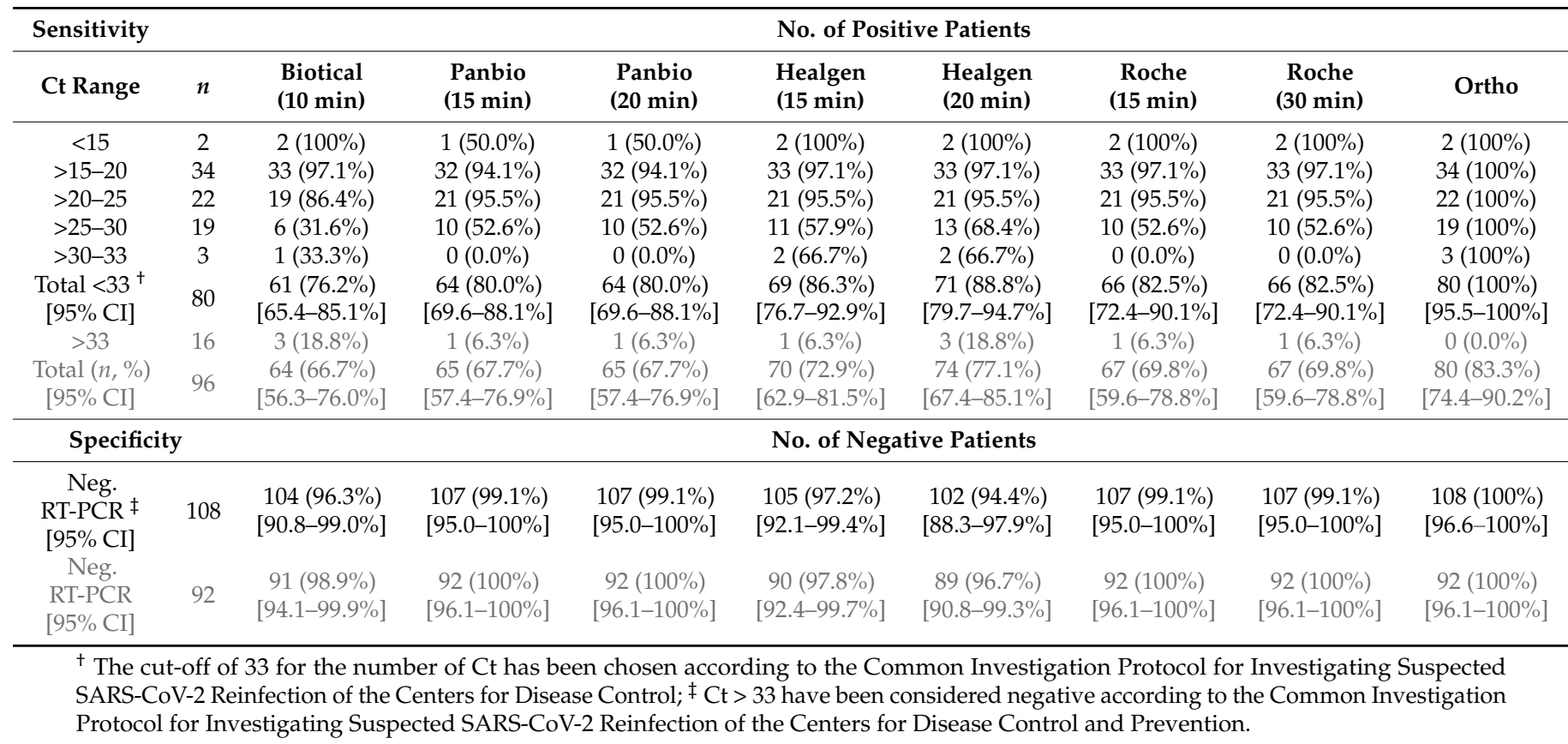

\subsection{Ortho Sensitivity}

The VITROS automated AG test showed a sensitivity of $100 \%$ for Ct values $\leq 33$ (Table 2). Considering a Ct value of 35, the sensitivity slightly decreased to $96.4 \%$ (95\%CI: 89.8-99.3\%) (Supplemental Table S2). Additionally, an excellent correlation between the antigen signal obtained on the VITROS automated assay and $\mathrm{Ct}$ values was observed $\left(\mathrm{R}^{2}=0.94 ; p<0.0001\right)$. The precision of the assay was excellent with within-run CVs of $2.3 \%, 1.8 \%$, and $3.1 \%$ at $\mathrm{Ct}$ values of $20.7,23.4$, and 30.9 , respectively.

\subsection{Antigen Detection Tests Specificity}

The specificities for the Biotical, the Panbio, the Healgen, and the Roche RAD were $98.9 \%, 100 \%, 97.8 \%$, and $100 \%$ when results were read after 10-15 min (depending on the test) in samples rendered negative by the RT-PCR. Due to the discrepancies in some samples between the different reading times, it decreased to $96.8 \%$ for the Healgen at $20 \mathrm{~min}$. When considering a Ct value of 33 as a surrogate of SARS-COV-2 contagiousness, specificities decreased for all RAD tests (Table 2). For the VITROS automated assay, none of the negative RT-PCR samples had a result above the cut-off signal of 1 , meaning that the specificity reached $100 \%$. Results were the same when considering a $\mathrm{Ct}$ value of 33 as the threshold for negativity.

\subsection{Negative Predictive Value, Positive Predictive Value, and Accuracy}

For the RAD tests, simulations showed that, at low disease prevalence, e.g., $2 \%$, the PPV was low (from $24.6 \%$ to $64.5 \%$ ) while the NPV was high (from $99.5 \%$ to $99.8 \%$ ). At high disease prevalence, e.g., $25 \%$, the PPV increased to 84.2 to $96.7 \%$ while the NPV decreased to 92.4 to $96.2 \%$. The automated AD test, with its sensitivity and specificity of $100 \%$ at the cut-off Ct of 33, showed a PPV and NPV, and an accuracy of 100\% (95\% CI: $98.1 \%$ to $100 \%$ ), respectively (Supplemental Table S3).

\section{Discussion}

This study compared and analyzed the clinical performance of $5 \mathrm{AD}$ tests, including the automated assay from Ortho Clinical Diagnostics. The RAD tests were most effective 
to identify RT-PCR positive symptomatic patients or asymptomatic subjects with higher viral loads (i.e., $\mathrm{Ct}$ values $\leq 25$ ). The sensitivity of these RAD tests for samples with a Ct values $\leq 25$ was $93.1 \%$ for the Biotical and the Panbio assays, while it was $96.6 \%$ for the Healgen and the Roche assays. Only the Biotical assay missed an asymptomatic patient with a $\mathrm{Ct}$ value of 23.4. For $\mathrm{Ct}$ values comprised between 25 and 30, all RAD tests were not able to detect three asymptomatic subjects with $\mathrm{Ct}$ values of 25.5, 26.3, and 29.3, respectively. Sensitivities decreased proportionally with higher $\mathrm{Ct}$ values. The best sensitivity was observed with the Healgen assay (i.e., $88.8 \%$ for samples with Ct values $\leq 33$ ). The VITROS automated assay outclassed all RAD tests with a sensitivity and a specificity of $100 \%$ for Ct values up to 33 (Table 2). The fact that the VITROS assay presented better performance compared to RAD tests is certainly related to an increased limit of quantification made possible by the chemiluminescent technology used.

In the literature, we identified at least four studies that evaluated the Panbio COVID$19 \mathrm{Ag}$ rapid test $[8,12,14,17,22]$. In a population of 341 patients, Fenollar et al. found a specificity of $94.9 \%$ and a good sensitivity but only for samples with $\mathrm{Ct}$ values $<25$ (i.e., 94.2 to $100 \%$ ) [12]. In a smaller cohort of 51 RT-PCR positive patients, Lanser et al. found a sensitivity of $85.8 \%$ in $\mathrm{Ct}$ values $<25$ [3]. Albert et al. confirmed a high specificity (i.e., $100 \%$ ) with an overall sensitivity of $79.6 \%$ in a population of 54 RT-PCR positive patients. For $\mathrm{Ct}$ values $<25$, the sensitivity increased above 95\% [8]. The same conclusion was found by Mak et al., using only 35 specimens [17]. The lower sensitivity observed with higher Ct values is in line with our evaluation (Table 2). Krüttgen et al. evaluated the Roche SARS-CoV-2 Rapid Antigen Test on a population of 75 patients with a positive RT-PCR and 75 with a negative RT-PCR and found a specificity of $96 \%$ and a $100 \%$ specificity in samples with $\mathrm{Ct}$ values lower than 25 [13]. Using the same assay, Salvagno et al. found a sensitivity ranging from 97 to $100 \%$ for specimens with $\mathrm{Ct}$ values $<25$, but lower sensitivities for higher $\mathrm{Ct}$ values (i.e., $50-81 \%$ for $\mathrm{Ct}$ values of 25 to <30) [23]. These results are also consistent with the data obtained in this study. Of note, this study is the first to evaluate the Biotical and Healgen RAD tests.

Our study is also the first to evaluate the new automated AD test provided by Ortho Clinical Diagnostics. Compared to RAD tests, the sensitivity of the test was $100 \%$ for $\mathrm{Ct}$ values up to 33, and the specificity of the test was 100\% (Table 2). The assay only missed three patient samples for $\mathrm{Ct}$ values up to 35 (i.e., at $\mathrm{Ct}$ values of 33.2, 34.1, and 34.5) (Supplemental Table S2). Interestingly, we observed an excellent correlation between the antigen signal and Ct values obtained by RT-PCR (Figure 2). Hirotsu et al. evaluated another automated AG test, namely the LUMIPULSE SARS-CoV-2 Ag kit (Fujirebio, Tokyo, Japan), performed on a LUMIPULSE G600II chemiluminescent assay [29]. Out of 58 RT-PCR positive patients, $26(44.8 \%)$ were negative on the LUMIPULSE. The specificity of the test ranged from $97.3 \%$ to $99.6 \%$ [29,30]. They also observed a weaker correlation with viral load (i.e., $R^{2}=0.77$ ) compared to our evaluation with the VITROS automated assay (i.e., $R^{2}=0.94$ ), which in our hands, showed excellent clinical performance.

In the scientific literature, there is an ongoing debate regarding the $\mathrm{Ct}$ value corresponding to the threshold of infectivity (i.e., patient considered as contagious) [26]. Bullard et al. showed that SARS-CoV-2 Vero cell infectivity was only observed for RT-PCR $\mathrm{Ct}$ value $<24$ in samples obtained less than eight days since symptom onset [4]. Albert et al. also found that SARS-CoV-2 could not be cultured from positive RT-PCR samples with $\mathrm{Ct}$ value $>25$. The same observation was made for samples positive using RT-PCR but negative using the Panbio RAD test $(n=11)$ [8]. However, in a larger cohort, Singanayagam et al. reported that a $\mathrm{Ct}$ value of 25 was still correlated to $80 \%$ of positive cultures and that only $8 \%$ of samples had a positive culture for Ct value $>35$ [28]. Jaafar et al. also showed that up to $70 \%$ of cultures were positive for a $\mathrm{Ct}$ value of 25 , and only $3 \%$ of cultures were positive for a Ct value $>35$ [25]. La Scola et al. found that patients with Ct value $>33-34$ are not contagious because of the low number of positive cultures [27]. This is consistent with the Centers for Disease Control and Prevention (CDC) recommendations, which propose a Ct value of 33 as a surrogate of contagiousness [24]. Based on these studies and on 
CDC recommendations, we calculate the performance of the five AG tests at the different proposed cut-offs for contagiousness (Table 2, Supplemental Tables S1-S3).

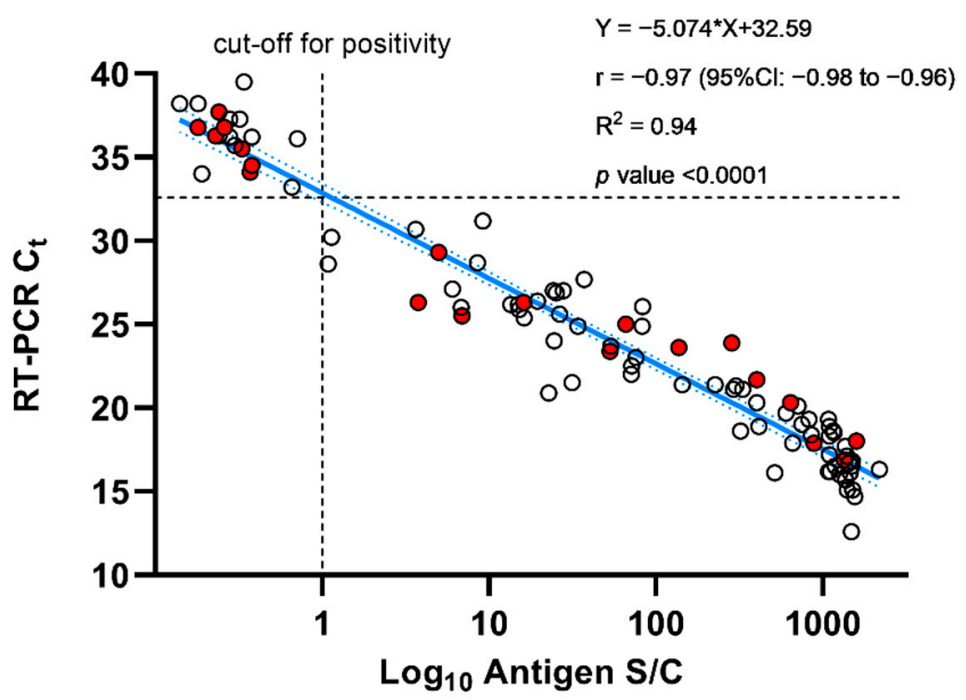

Figure 2. Linear regression of $\mathrm{Ct}$ values obtained by RT-PCR versus the amount of antigen $\left(\log _{10}\right.$ transformed S/C results) obtained on the VITROS assay. Samples from asymptomatic subjects are highlighted in red.

The main advantages of RAD tests are their rapidity, and their ease of interpretation, and the limited technical skill/infrastructure requirements. Moreover, the use of RAD tests in mass screening programs could decrease the burden on laboratories that have been overwhelmed during the last COVID-19 pandemics [9]. Nevertheless, it is important to keep in mind that even with a high viral load (i.e., Ct values $<25$ ), a RAD test can result in false-negative estimates in both symptomatic patients and asymptomatic subjects $[12,13,17,20-23]$. Mass community screening would, therefore, require the use of more sensitive techniques.

The performance of the VITROS automated assay outclassed the ones of RAD tests. Based on the categorization proposed by Kost and considering a Ct value of 33 [31], the VITROS automated assay can be placed in the "Tier 3" category, meaning that the assay has high sensitivity and specificity (i.e., 100\%), leading to high NPV and PPV whatever the prevalence of the disease (Supplemental Table S3).

In most laboratories using RT-PCR for diagnosis, the VITROS automated assay could be used as a routine high-throughput test in a clinical setting with an approximative cadence of 150 samples per hour. More importantly, according to the CDC cut-off, the VITROS automated assay may replace the RT-PCR for the detection of positive cases thanks to its excellent performance at the $\mathrm{Ct}$ value of 33 . However, compared to RAD tests that can be used in any facility, an automated test obviously requires specialized equipment.

These analytical and clinical performance have to be interpreted together with the prevalence of the disease. While some studies have discussed the importance of the disease prevalence for serological testing [31], few have discussed the importance of the disease prevalence in the performance of $\mathrm{AD}$ tests. Simulations showed that, at low disease prevalence, e.g., $2 \%$, the PPV was low $(24.6 \%$ to $64.5 \%)$ while the NPV was high $(99.5 \%$ to $99.8 \%$ ). At high disease prevalence, e.g., $25 \%$, the PPV increased from $84.2 \%$ to $96.7 \%$ while the NPV decreased from $92.4 \%$ to $96.2 \%$. Consequently, RAD tests are not appropriate for mass community screening since they will lead to a high rate of false-positive and negative results. On the opposite, the VITROS assay showed remarkable performance with PPV and NPV of $100 \%$ both.

While this study confirms that RAD tests have limited performance and should only be used in facilities where access to RT-PCR or automated AD is not possible within 
an appropriate timeframe, further studies are needed to confirm our data on a larger population. In addition, a global consensus is also needed to define the $\mathrm{Ct}$ value that could be used as a surrogate of infectivity and contagiousness [2].

\section{Conclusions}

The RAD tests showed an acceptable sensitivity only for samples with Ct values corresponding to higher viral loads (i.e., <25). However, even with such high viral loads, some samples were miscategorized both from symptomatic patients and asymptomatic subjects. For $\mathrm{Ct}$ values between 25 and 30, only the VITROS automated assay showed a sufficient sensitivity. If considering a $\mathrm{Ct}$ value of 33 as a surrogate of contagiousness, the VITROS automated test performed the best ( $100 \%$ sensitivity) while RAD tests reported insufficient sensitivity. The highest specificity was also observed using the VITROS automated assay (i.e., 100\%), which could be proposed as a first-line testing method for the detection of potential contagious cases.

Supplementary Materials: The following are available online at https://www.mdpi.com/2077-0 383/10/2/265/s1, Table S1: Sensitivity and specificity of RAD and automated antigen tests across different range of RT-PCR Ct values. Results in grey provide results of all RT-PCR values including those with a Ct value >25 (min-max range: 12.6-38.2), Table S2: Sensitivity and specificity of RAD and automated antigen tests across different range of RT-PCR Ct values. Results in grey provide results of all RT-PCR values including those with a Ct value $>35$ (min-max range: 12.6-38.2), Table S3: Positive predictive values (PPV), negative predictive values (NPV) and accuracies were simulated at different disease prevalence to estimate the performance of the antigenic tests in « real-life » conditions. Ct value $>33$ was not considered a true positive case. ${ }^{*}$ As the sensitivity and the specificity were $100 \%$ both, no confidence intervals have been calculated for the PPV and the NPV.

Author Contributions: Conceptualization, J.F. and J.D.; Data curation, J.F.; Formal analysis, J.F. and J.D.; Investigation, J.F. and J.D.; Methodology, J.F., C.G., M.O., C.E., L.M. and J.D.; Resources, J.F. and J.D.; Software, J.F.; Supervision, J.F. and J.D.; Visualization, J.F.; Writing —original draft, J.F.; Writing-review \& editing, C.G., M.O., J.C., M.E., C.E., K.L., C.R., S.V.E., J.-B.N., L.M., J.-M.D. and J.D. All authors have read and agreed to the published version of the manuscript.

Funding: This research received no external funding.

Institutional Review Board Statement: The study was conducted according to the guidelines of the Declaration of Helsinki, and approved by the Medical Ethical Committee of Saint-Luc Bouge (protocol code B0392020000005, 15 April 2020).

Informed Consent Statement: Informed consent was obtained from all subjects involved in the study.

Data Availability Statement: The data presented in this study are available on request from the corresponding author. The data are not publicly available due to ethical issue.

Acknowledgments: We would like to thank Romain Siriez for his technical help.

Conflicts of Interest: Among the authors, J.D. is CEO and founder of QUALIblood s.a., a contract research organization manufacturing the DP-Filter, is co-inventor of the DP-Filter (patent application number: PCT/ET2019/052903) and reports personal fees from Daiichi-Sankyo, Gedeon Richter, Mithra Pharmaceuticals, Stago, Roche and Roche Diagnostics outside the submitted work. The other authors have no conflict of interest to disclose.

\section{References}

1. Vashist, S.K. In Vitro Diagnostic Assays for COVID-19: Recent Advances and Emerging Trends. Diagnostics 2020, 10, 202. [CrossRef] [PubMed]

2. Buchta, C.; Görzer, I.; Chiba, P.; Camp, J.V.; Holzmann, H.; Puchhammer-Stöckl, E.; Mayerhofer, M.; Muller, M.M.; Aberle, S.W. Variability of cycle threshold values in an external quality assessment scheme for detection of the SARS-CoV-2 virus genome by RT-PCR. Clin. Chem. Lab. Med. (CCLM) 2020. [CrossRef]

3. Lanser, L.; Bellmann-Weiler, R.; Ottl, K.W.; Huber, L.; Griesmacher, A.; Theurl, I.; Weiss, G. Evaluating the clinical utility and sensitivity of SARS-CoV-2 antigen testing in relation to RT-PCR Ct values. Infection 2020. [CrossRef] [PubMed] 
4. Bullard, J.; Dust, K.; Funk, D.; Strong, J.E.; Alexander, D.; Garnett, L.; Boodman, C.; Bello, A.; Hedley, A.; Schiffman, Z.; et al. Predicting infectious SARS-CoV-2 from diagnostic samples. Clin. Infect. Dis. 2020. [CrossRef]

5. Bohn, M.K.; Loh, T.P.; Wang, C.B.; Mueller, R.; Koch, D.; Sethi, S.; Rawlinson, W.D.; Clementi, M.; Erasmus, R.; Lepotier, M.; et al. IFCC interim guidelines on serological testing of antibodies against SARS-CoV-2. Clin. Chem. Lab. Med. 2020, 58, 2001-2008. [CrossRef] [PubMed]

6. Centers for Disease Control. Interim Guidelines for Covid-Antibody Testing. 2020. Available online: https:/ /www.cdc.gov/ coronavirus / 2019-ncov/lab/resources/antibody-tests-guidelines.html (accessed on 25 December 2020).

7. FindDx. Sars-CoV-2 Diagnostics Pipeline. 2020. Available online: https://www.finddx.org/covid-19/pipeline/ (accessed on 25 December 2020).

8. Albert, E.; Torres, I.; Bueno, F.; Huntley, D.; Molla, E.; Fernandez-Fuentes, M.A.; Martinez, M.; Poujois, S.; Forque, L.; Valdivia, A.; et al. Field evaluation of a rapid antigen test (Panbio COVID-19 Ag Rapid Test Device) for COVID-19 diagnosis in primary healthcare centers. Clin. Microbiol. Infect. 2020. [CrossRef]

9. Cerutti, F.; Burdino, E.; Milia, M.G.; Allice, T.; Gregori, G.; Bruzzone, B.; Ghisetti, V. Urgent need of rapid tests for SARS CoV-2 antigen detection: Evaluation of the SD-Biosensor antigen test for SARS-CoV-2. J. Clin. Virol. 2020, 132, 104654. [CrossRef]

10. Diao, B.; Wen, K.; Zhang, J.; Chen, J.; Han, C.; Chen, Y.; Want, S.; Deng, G.; Zhou, H.; Wu, Y. Accuracy of a nucleocapsid protein antigen rapid test in the diagnosis of SARS-CoV-2 infection. Clin. Microbiol. Infect. 2020. [CrossRef]

11. Dinnes, J.; Deeks, J.J.; Adriano, A.; Berhane, S.; Davenport, C.; Dittrich, S.; Emperador, D.; Takwoingi, Y.; Cunningham, J.; Beese, S.; et al. Rapid, point-of-care antigen and molecular-based tests for diagnosis of SARS-CoV-2 infection. Cochrane Database Syst. Rev. 2020. [CrossRef]

12. Fenollar, F.; Bouam, A.; Ballouche, M.; Fuster, L.; Prudent, E.; Colson, P.; Tissot-Dupont, H.; Million, M.; Drancourt, M.; Raoult, D.; et al. Evaluation of the Panbio Covid-19 rapid antigen detection test device for the screening of patients with Covid-19. J. Clin. Microbiol. 2020. [CrossRef] [PubMed]

13. Kruttgen, A.; Cornelissen, C.G.; Dreher, M.; Hornef, M.W.; Imohl, M.; Kleines, M. Comparison of the SARS-CoV-2 Rapid Antigen Test to the Real Star Sars-CoV-2 RT PCR Kit. J. Virol. Methods 2020, 288, 114024. [CrossRef] [PubMed]

14. Linares, M.; Perez-Tanoira, R.; Carrero, A.; Romanyk, J.; Perez-Garcia, F.; Gomez-Herruz, P.; Arroyo, T.; Cuadros, J. Panbio antigen rapid test is reliable to diagnose SARS-CoV-2 infection in the first 7 days after the onset of symptoms. J. Clin. Virol. 2020, 133, 104659. [CrossRef] [PubMed]

15. Liotti, F.M.; Menchinelli, G.; Lalle, E.; Palucci, I.; Marchetti, S.; Colavita, F.; La Sorda, M.; Sberna, G.; Bordi, L.; Sanguinetti, M.; et al. Performance of a novel diagnostic assay for rapid SARS-CoV-2 antigen detection in nasopharynx samples. Clin. Microbiol. Infect. 2020. [CrossRef] [PubMed]

16. Liu, D.; Ju, C.; Han, C.; Shi, R.; Chen, X.; Duan, D.; Yan, J.; Yan, X. Nanozyme chemiluminescence paper test for rapid and sensitive detection of SARS-CoV-2 antigen. Biosens. Bioelectron. 2020, 173, 112817. [CrossRef] [PubMed]

17. Mak, G.C.; Lau, S.S.; Wong, K.K.; Chow, N.L.; Lau, C.S.; Lam, E.T.; Chan, R.C.W.; Tsnag, D.N.C. Analytical sensitivity and clinical sensitivity of the three rapid antigen detection kits for detection of SARS-CoV-2 virus. J. Clin. Virol. 2020, 133, 104684. [CrossRef]

18. Ogata, A.F.; Maley, A.M.; Wu, C.; Gilboa, T.; Norman, M.; Lazarovits, R.; Mao, C.-P.; Newton, G.; Chang, M.; Nguyen, K.; et al. Ultra-sensitive Serial Profiling of SARS-CoV-2 Antigens and Antibodies in Plasma to Understand Disease Progression in COVID19 Patients with Severe Disease. Clin. Chem. 2020. [CrossRef]

19. Scohy, A.; Anantharajah, A.; Bodeus, M.; Kabamba-Mukadi, B.; Verroken, A.; Rodriguez-Villalobos, H. Low performance of rapid antigen detection test as frontline testing for COVID-19 diagnosis. J. Clin. Virol. 2020, 129, 104455. [CrossRef]

20. Yamayoshi, S.; Sakai-Tagawa, Y.; Koga, M.; Akasaka, O.; Nakachi, I.; Koh, H.; Maeda, K.; Adachi, E.; Saito, M.; Nagai, H.; et al. Comparison of Rapid Antigen Tests for COVID-19. Viruses 2020, 12, 1420. [CrossRef]

21. Mak, G.C.; Cheng, P.K.; Lau, S.S.; Wong, K.K.; Lau, C.; Lam, E.T.; Chan, R.C.W.; Tsang, D.N.C. Evaluation of rapid antigen test for detection of SARS-CoV-2 virus. J. Clin. Virol. 2020, 129, 104500. [CrossRef]

22. Mak, G.C.K.; Lau, S.S.Y.; Wong, K.K.Y.; Chow, N.L.S.; Lau, C.S.; Lam, E.T.K.; Chan, R.C.W.; Tsang, D.N.C. Evaluation of rapid antigen detection kit from the WHO Emergency Use List for detecting SARS-CoV-2. J. Clin. Virol. 2021, 134, 104712. [CrossRef]

23. Salvagno, G.L.; Gianfilippi, G.; Bragantini, D.; Henry, B.M.; Lippi, G. Clinical assessment of the Roche SARS-CoV-2 rapid antigen test. Diagnosis 2020. [CrossRef]

24. Centers for Disease Control and Prevention. Common Investigation Protocol for Investigating Suspected SARS-CoV-2 Reinfection. 2020. Available online: https:/ / www.cdc.gov/coronavirus/2019-ncov/php/reinfection.html (accessed on 25 December 2020).

25. Jaafar, R.; Aherfi, S.; Wurtz, N.; Grimaldier, C.; Hoang, V.T.; Colson, P.; Raoult, D.; La Scola, B. Correlation between 3790 qPCR positives samples and positive cell cultures including 1941 SARS-CoV-2 isolates. Clin. Infect. Dis. 2020. [CrossRef] [PubMed]

26. Jefferson, T.; Spencer, E.; Brassey, J.; Heneghan, C. Viral cultures for COVID-19 infectivity assessment-A systematic review. medRxiv. 2020. [CrossRef]

27. La Scola, B.; Le Bideau, M.; Andreani, J.; Hoang, V.T.; Grimaldier, C.; Colson, P.; Gautret, P.; Raoult, D. Viral RNA load as determined by cell culture as a management tool for discharge of SARS-CoV-2 patients from infectious disease wards. Eur. J. Clin. Microbiol. Infect. Dis. 2020, 39, 1059-1061. [CrossRef]

28. Singanayagam, A.; Patel, M.; Charlett, A.; Lopez Bernal, J.; Saliba, V.; Ellis, J.; Ladhani, S.; Zambon, M.; Gopal, R. Duration of infectiousness and correlation with RT-PCR cycle threshold values in cases of COVID-19, England, January to May 2020. Eurosurveillance 2020, 25, 2001483. [CrossRef] [PubMed] 
29. Hirotsu, Y.; Maejima, M.; Shibusawa, M.; Nagakubo, Y.; Hosaka, K.; Amemiya, K.; Sueki, H.; Hayakawa, M.; Mochizuki, H.; Tsutsui, T.; et al. Comparison of automated SARS-CoV-2 antigen test for COVID-19 infection with quantitative RT-PCR using 313 nasopharyngeal swabs, including from seven serially followed patients. Int. J. Infect. Dis. 2020, 99, 397-402. [CrossRef] [PubMed]

30. Ogawa, T.; Fukumori, T.; Nishihara, Y.; Sekine, T.; Okuda, N.; Nishimura, T.; Fujikura, H.; Hirai, N.; Imakita, N.; Kasahara, K. Another false-positive problem for a SARS-CoV-2 antigen test in Japan. J. Clin. Virol. 2020, 131, 104612. [CrossRef] [PubMed]

31. Kost, G.J. Designing and Interpreting COVID-19 Diagnostics: Mathematics, Visual Logistics, and Low Prevalence. Arch. Pathol. Lab. Med. 2020. [CrossRef] 